\title{
Antioxidant Potential of the Polyphenolics in Grewia asiatica, Eugenia jambolana and Carissa carandas
}

\author{
Rahmanullah Siddiqi ${ }^{1}$, Shahina Naz ${ }^{1}$, Syed Asad Sayeed ${ }^{1}$, Shagufta Ishteyaque ${ }^{2}$, Muhammad Samee Haider ${ }^{3}$, \\ Omer Mukhtar Tarar ${ }^{3} \&$ Khalid Jamil ${ }^{3}$ \\ ${ }^{1}$ Department of Food Science \& Technology, University of Karachi, Karachi, Pakistan \\ ${ }^{2}$ Department of Chemical Engineering, University of Karachi, Karachi, Pakistan \\ ${ }^{3}$ Food Technology Section, Food and Marine Resources Research Centre, PCSIR Laboratories Complex, Karachi, \\ Pakistan \\ Correspondence: Rahmanullah Siddiqi, Department of Food Science \& Technology, University of Karachi, \\ Karachi, Pakistan. E-mail: rahman_siddiqi@yahoo.co.uk, rahman.siddiqi@uok.edu.pk
}

Received: September 29, 2012 Accepted: October 23, 2012 Online Published: February 17, 2013

doi:10.5539/jas.v5n3p217

URL: http://dx.doi.org/10.5539/jas.v5n3p217

\begin{abstract}
The fruits G. asiatica, E. jambolana and C. carandas were extracted with methanol and the extracts were partitioned into four polyphenolic fractions: Flavanols, flavonols, phenolic acids and anthocyanins using solid phase extraction. Each fraction was then analyzed for total phenolics, flavonoids, antioxidant activity by DPPH, $\beta$-carotene-linoleic acid assay and total reducing power. Total phenolics ranged 6.64-107, 56.20-398, 33.38-315 and $20-201 \mathrm{mg} / 100 \mathrm{~g}$ in phenolic acid, flavanol, flavonol and anthocyanin fractions respectively of these fruits which explained the order of their antioxidant activity and reducing power as flavanols $>$ flavonols $>$ anthocyanins $>$ phenolic acid. Total phenolics were highest in E. jambolana fractions (107-398 mg/100 g) but the maximum antioxidant activity $(62-85 \%$ in 2,2-diphenyl-1-picrylhydrazyl (DPPH) and $58-89 \%$ in $\beta$-carotene-linoleic acid assay) was shown by the fractions in G.asiatica (total phenolics, $67-151 \mathrm{mg} / 100 \mathrm{~g}$ ). At all concentrations, the DPPH scavenging activity of flavanol fraction in G. asiatica $(85 \%$ at $20 \mathrm{ppm})$ was comparable to BHA ( $89 \%)$.
\end{abstract}

Keywords: Grewia asiatica, Eugenia jambolana, Carissa carandas, polyphenols, antioxidant activity

\section{Introduction}

The over production of active oxygen species like $\mathrm{O}_{2}, \mathrm{H}_{2} \mathrm{O}_{2}$ and $\mathrm{OH}^{-}$may lead to tissue injury (Thomas, 1995), DNA damage, thiol oxidation and lipid peroxidation (Halliwell et al., 1995), cardiac disorder, chronic gut inflammation, cancer and AIDS in humans (Halliwell et a1., 1992). An antioxidant is known to delay or prevent oxidation of substrate (Halliwell, 1990). The role of polyphenols as radical scavengers and in increasing the resistance of LDL oxidation involved in heart diseases (Rice-Evans et al., 1995) have been demonstrated by many in vitro studies. Flavonoids, a family of polyphenolic compounds, are widely distributed pigments, possessing anti-radical and chelating properties. They can scavenge free hydroxyl and peroxy radicals or may extract iron ions to depress superoxide-driven Fenton reaction (Afanas'ev et al., 1989). It is established that antioxidant potential of lots of fruits is based on their flavonoid contents (Wang et al., 1996; Heinonen et al., 1998 ) and polyphenolics in foods are more efficient antioxidants than vitamins C \& E, and $\beta$-carotene (Vinson et al., 1995).

There are various methods to assess the in vitro antioxidant potential of isolated compounds involving different mechanisms, for instance, scavenging of reactive oxygen species or reactive nitrogen species like peroxynitrite, the $\mathrm{OH}$ radical and superoxide, measuring the vanishing of free radicals such as $\mathrm{ABTS}^{+}$ (2,2'-azinobis-(3-ethyl-benzothiazoline-6-sulphonate) cation radical) or DPPH (2,2-diphenyl-1-picrylhydrazyl) and determining the total antioxidant power like ferric reducing/antioxidant power. A number of techniques may be used for measuring differences between the antioxidant potential of the compounds. Since most of the compounds tested are multifunctional, therefore it is necessary to measure more than one property (Frankel \& Meyer, 2000). Thus the results of antioxidant capacity rely on the procedure used and a single method may not be sufficient enough to predict antioxidant efficacy of the various compounds or extracts. Studies have been 
performed to evaluate the role of Grewia asiatica, Eugenia jambolana and Carissa carandas extracts in different chemical in vitro models. None of the studies have reported the antioxidant activities associated to the various polyphenolic fractions of G. asiatica and C. carandas separated from the crude extracts on the basis of their chemistry. Several studies have reported the isolation of polyphenolic compounds with their respective antioxidant capacities in E. jambolana but the way the fractionation has been performed, types of the fractions separated on the basis of their chemical nature and the correlation of total phenolics, flavonoids, anthocyanins in each fraction with their antioxidant activities presented in this study is quite different and new.

\section{Materials and Methods}

\subsection{Sampling}

Sample fruits - G. asiatica and E. jambolana - were purchased once in a size of $10 \mathrm{~kg}$ each in May and June 2009 respectively. About $12 \mathrm{~kg}$ of C. carandas fruits were collected in July from Karachi University campus Sample fruits - being very perishable in nature and sold within 1-2 days after harvesting, were stored immediately at $-5^{\circ} \mathrm{C}$ after washing and packing.

\subsection{Extraction and Fractionation of Polyphenolics}

Extraction, fractionation of polyphenols into anthocyanins (Fraction II) and non anthocyanins and further division of non anthocyanin fraction into flavanols (Fraction Ia), flavonols (Fraction Ib) and phenolic acids (Fraction Ic) were performed as described by Siddiqi et al. (2011).

\subsection{Quantitative Analyses of the Fractions Ia, Ib, Ic and II}

All the fractions were analysed in triplicate for total phenols and flavonoids by the method of Jayaprakasha et al. (2003) and Zhishen et al. (1999) respectively and the data were expressed as mean \pm standard error. Fraction II was also analysed spectrophotometrically by the $\mathrm{pH}$ differential method for total anthocyanins (Wrolstad et al., 2005).

\subsection{Antioxidative Potential}

Antioxidant activities of all the extracts were determined by three different methods- DPPH radical scavenging system (Miliauskas et al., 2004), $\beta$-carotene-linoleic acid assay (Skerget et al., 2005) and ferric reducing assay (Jayaprakasha et al., 2001).

\subsection{Statistical Analyses}

All of the experiments were performed in triplicate, and the data were expressed as the mean \pm SEM. Differences in antioxidant activity of the fractions were analyzed for significance using one-way analysis of variation (ANOVA) followed by a Bonferroni test for multiple comparisons using Originlab 8.0.

\section{Results and Discussion}

All the fractions showed potent radical-scavenging activity. The results of the activity of the four fractions and butylated hydroxyl anisole (BHA) are shown in Table 1 . The radical scavenging activity of the fractions varied from $61-85 \%$ for G. asitica, $50-78 \%$ for E. jambolana and $41-70 \%$ for C. carandas at $20 \mathrm{ppm}(p<0.05)$. The maximum activity was noted in G. asiatica fractions and the minimum in E. jambolana fractions. In all fractions the activity increased significantly with concentration $(p<0.05)$. Though the total phenolics and flavonoids were higher in E. jambolana, the antioxidant activities of $G$. asiatica fractions were relatively higher $(p<0.05)$. The order of antioxidant activity of the fractions was corresponding to their order of phenolic and flavonoid contents i.e., Fraction Ib $>$ Fraction Ic $>$ Fraction II $>$ Fraction Ia (Table 2) in all three fruits. At all concentrations, the activity of Fraction Ib from G. asitica was comparable to BHA. Fraction Ib of E. jambolana and C. carandas also showed good radical scavenging activity. 
Table 1. Rdical scavenging activities of the fractions derived from G. asiatica, E. jambolana and C.carandas by DPPH method

\begin{tabular}{clcccc}
\hline Fruit Sample & Fractions & \multicolumn{3}{l}{ Concentration of fractions } \\
\hline & & $\mathbf{5 p p m}$ & $\mathbf{1 0} \mathbf{p p m}$ & $\mathbf{1 5} \mathbf{p p m}$ & $\mathbf{2 0} \mathbf{p p m}$ \\
\hline \multirow{4}{*}{ G. asiatica } & Fraction Ia & $24 \pm 0.23$ & $38 \pm 1.60$ & $48 \pm 0.8$ & $62 \pm 0.67$ \\
& Fraction II & $30 \pm 0.89$ & $50 \pm 0.98$ & $58 \pm 0.67$ & $70 \pm 0.98$ \\
& Fraction Ic & $39 \pm 1.20$ & $58 \pm 1.30$ & $62 \pm 1.45$ & $78 \pm 1.23$ \\
& Fraction Ib & $48 \pm 2.30$ & $62 \pm 1.56$ & $75 \pm 1.89$ & $85 \pm 3.23$ \\
\hline \multirow{3}{*}{ jambolana } & Fraction Ia & $15 \pm 0.67$ & $30 \pm 0.23$ & $41 \pm 0.56$ & $50 \pm 2.03$ \\
& Fraction Ib & $25 \pm 0.34$ & $45 \pm 0.34$ & $50 \pm 0.45$ & $67 \pm 1.20$ \\
& Fraction Ic & $31 \pm 0.20$ & $50 \pm 0.56$ & $58 \pm 0.32$ & $68 \pm 2.30$ \\
& Fraction II & $42 \pm 0.17$ & $55 \pm 0.23$ & $68 \pm 0.23$ & $78 \pm 1.45$ \\
\hline \multirow{2}{*}{ carandas } & Fraction Ia & $10 \pm 1.23$ & $27 \pm 0.56$ & $35 \pm 0.23$ & $41 \pm 0.56$ \\
& Fraction Ib & $21 \pm 0.78$ & $33 \pm 0.34$ & $48 \pm 0.45$ & $62 \pm 1.20$ \\
& Fraction Ic & $28 \pm 0.96$ & $42 \pm 0.23$ & $51 \pm 0.56$ & $65 \pm 2.30$ \\
& Fraction II & $40 \pm 0.23$ & $50 \pm 0.12$ & $61 \pm 0.78$ & $70 \pm 1.45$ \\
\hline BHA & & $52 \pm 3.20$ & $68 \pm 1.23$ & $78 \pm 2.6$ & $89 \pm 3.50$ \\
\hline
\end{tabular}

Means \pm SEM of triplicate assays. For a given fruit sample, values in the same column and row were significantly different at $p<0.05$.

Table 2. Anthocyanin, flavonoid and total phenolic contents (data expressed as milligrams per $100 \mathrm{~g}$ of weight) (Siddiqi et al., 2011)

\begin{tabular}{ccccc}
\hline Fruit Sample & Fractions & Total phenolics $^{\mathrm{a}}$ & Flavonoids $^{\mathrm{b}}$ & Anthocyanins $^{\mathrm{c}}$ \\
\hline & Fraction Ia & $67 \pm 0.98$ & - & - \\
& Fraction Ib & $288 \pm 0.07$ & $178 \pm 0.23$ & - \\
& Fraction Ic & $222 \pm 1.90$ & $165 \pm 0.23$ & - \\
G. asiatica & Fraction II & $151 \pm 0.40$ & $100 \pm 0.90$ & $72 \pm 6.0$ \\
\hline & Fraction Ia & $107 \pm 0.20$ & - & - \\
& Fraction Ib & $398 \pm 0.21$ & $287 \pm 0.24$ & - \\
& Fraction Ic & $315 \pm 0.41$ & $256 \pm 1.30$ & - \\
E. jambolana & Fraction II & $201 \pm 0.51$ & $151 \pm 0.34$ & $13 \pm 0.31$ \\
\hline & Fraction Ia & $6.64 \pm 0.14$ & & - \\
& Fraction Ib & $56.20 \pm 0.2$ & $36 \pm 0.092$ & - \\
& Fraction Ic & $33.38 \pm 0.4$ & $17.0 \pm 0.01$ & - \\
C. carandas & Fraction II & $20 \pm 0.210$ & $9 \pm 0.660$ & $6.45 \pm 0.36$
\end{tabular}

(-) estimation not performed

Means \pm SEM of triplicate assays. Values in the same column were significantly different at $p<0.05$ ${ }^{a}$ Concentration based upon gallic as standard. ${ }^{b}$ Concentration based upon catechin as standard. ${ }^{\mathrm{c}}$ Concentration based upon cyanidin-3-glucoside as standard. 
Table 3. Antioxidant activities of the G. asiatica, E. jambolana and $C$. carandas fractions using $\beta$-carotene-linoleic acid assay

\begin{tabular}{lccc}
\hline & & \% Inhibition \\
& G.asiatica & E.jumbolana & C.carandas \\
\hline Fraction Ia & $58 \pm 1.23$ & $50 \pm 0.98$ & $39 \pm 1.45$ \\
Fraction II & $65 \pm 2.30$ & $55 \pm 3.10$ & $48 \pm 2.09$ \\
Fraction Ic & $75 \pm 1.87$ & $65 \pm 1.34$ & $52 \pm 1.65$ \\
Fraction Ib & $89 \pm 2.00$ & $80 \pm 2.09$ & $61 \pm 0.98$
\end{tabular}

Values are represented as mean \pm standard error. Values in the same column and row were significantly different at $p<0.05$

All fractions of the fruits effectively inhibited the oxidation of $\beta$-carotene in the linolenic emulsion system $(p<0.05)$ (Table 3). Like DPPH, the highest inhibition of $\beta$-carotene oxidation was shown by G. asiatica fractions (58-89\%), while the lowest inhibition was shown by $C$. carandas fractions $(39-61 \%)$. $\mathrm{DPPH} \mathrm{IC}_{50}$ values of the successive extracts of $G$. asiatica leaves were found to be $249.60 \pm 7.37,16.19 \pm 2.132,26.17 \pm 1.49,27.38 \pm 1.80,176.14 \pm$ 5.53 and $56.40 \pm 3.98 \mu \mathrm{g} / \mathrm{mL}$ by Gupta et al. (2007). Our results show that the $\mathrm{DPPH} \mathrm{IC}_{50}$ values ranges between 5-20 ppm for G. asiatica fractions (Table1). Comparison of these results indicates that G. asiatica fruit has much more antioxidative potential than $G$. asiatica leaves. $\mathrm{DPPH} \mathrm{IC}_{50}$ of $8.6 \mu \mathrm{g} / \mathrm{mL}$ for E. jambolana fruit (at 192.3 $\mathrm{mg} \mathrm{GAE} / \mathrm{g}$ total phenols) reported by Hossain et al. (2008) and 78.2\% for fruit peel anthocyanins reported by Veigas (2007) at $2.5 \mathrm{ppm}$ are lower than our values which ranges 5-10 ppm for almost all the fractions (Table 1). The antioxidant activity is dependent upon the reducing ability (Tanaka et al., 1988). Table 4 shows the reducing power of the fractions using potassium ferricyanide reduction method. At $50 \mathrm{ppm}$ concentration, the absorbance at $700 \mathrm{~nm}$ ranged 1.56-3.1, 1.2-2.44 and 0.67-1.92 for G. asiatica, E. jambolana and C. carandas respectively.

Table 4. Reducing power of the fractions derived from G. asiatica, E. jambolana and C.carandas.

\begin{tabular}{ccccc}
\hline & Concentration & G.asiatica & E.jumbolana & C.carandas \\
\hline \multirow{2}{*}{ Fraction Ia } & $5 \mathrm{ppm}$ & $0.52 \pm 0.09^{1 \mathrm{a}}$ & $0.50 \pm 0.13^{1 \mathrm{a}}$ & $0.35 \pm 0.05$ \\
& $10 \mathrm{ppm}$ & $0.75 \pm 0.05$ & $0.65 \pm 0.03$ & $0.41 \pm 0.05$ \\
& $25 \mathrm{ppm}$ & $1.30 \pm 0.10$ & $0.80 \pm 0.02$ & $0.48 \pm 0.05$ \\
& $50 \mathrm{ppm}$ & $1.53 \pm 0.06$ & $1.25 \pm 0.04$ & $0.70 \pm 0.09$ \\
\hline \multirow{3}{*}{ Fraction II } & $5 \mathrm{ppm}$ & $0.80 \pm 0.02$ & $0.65 \pm 0.10$ & $0.60 \pm 0.10^{1 \mathrm{c}}$ \\
& $10 \mathrm{ppm}$ & $1.00 \pm 0.04^{\mathrm{b}}$ & $0.90 \pm 0.07^{\mathrm{b}}$ & $0.50 \pm 0.06^{1 \mathrm{c}}$ \\
& $25 \mathrm{ppm}$ & $1.60 \pm 0.10$ & $1.45 \pm 0.10$ & $0.61 \pm 0.05^{1 \mathrm{c}}$ \\
& $50 \mathrm{ppm}$ & $2.00 \pm 0.12$ & $1.75 \pm 0.04$ & $1.10 \pm 0.09$ \\
\hline \multirow{2}{*}{ Fraction Ic } & $5 \mathrm{ppm}$ & $0.85 \pm 0.09^{1 \mathrm{~d}}$ & $0.80 \pm 0.04^{1 \mathrm{~d}}$ & $0.70 \pm 0.08^{1 \mathrm{~d}}$ \\
& $10 \mathrm{ppm}$ & $1.40 \pm 0.13$ & $1.10 \pm 0.09$ & $0.60 \pm 0.09^{1 \mathrm{~d}}$ \\
& $25 \mathrm{ppm}$ & $2.00 \pm 0.05$ & $1.75 \pm 0.10$ & $1.00 \pm 0.06$ \\
& $50 \mathrm{ppm}$ & $2.60 \pm 0.10$ & $2.10 \pm 0.17$ & $1.70 \pm 0.12$ \\
\hline \multirow{2}{*}{ Fraction Ib } & $5 \mathrm{ppm}$ & $1.00 \pm 0.05$ & $0.85 \pm 0.07^{1 \mathrm{e}}$ & $0.82 \pm 0.04^{1 \mathrm{e}}$ \\
& $10 \mathrm{ppm}$ & $1.80 \pm 0.06$ & $1.25 \pm 0.08$ & $0.90 \pm 0.08$ \\
& $25 \mathrm{ppm}$ & $2.40 \pm 0.14$ & $2.00 \pm 0.12$ & $1.38 \pm 0.06$ \\
& $50 \mathrm{ppm}$ & $3.10 \pm 0.05$ & $2.55 \pm 0.11$ & $1.86 \pm 0.13$ \\
\hline
\end{tabular}

Values are represented as mean \pm standard error. Values in the same column and row were significantly different at $p<0.05$ except where the same superscripts have been used to show no significant difference. 
The reducing ability of G. asiatica was greater than that of E. jambolana and C. carandas $(p<0.05)$. The reducing property relates to the presence of reductones (Pin-Der, 1998) which not only break the free radical sequence by providing a single hydrogen but also quench peroxide formation by reacting with precursors of peroxide (Gordon, 1990). The results show that the evident antioxidant activity of the fractions from these three fruits were the consequence of their reducing potential and the ability to inhibit free radicals. The order of antioxidant activity of the fractions (Fraction Ib $>$ Fraction Ic $>$ Fraction II $>$ Fraction Ia) can be explained on the basis of total phenolic contents and the relationship between structure and antioxidant activity of flavonoids derived from the literature. Total phenolics were least in the Fraction Ia (Table 2). Relative antioxidant activity of phenolic acids and their esters is dependent on the number of hydroxyl groups in the molecule. The H-donating ability of hydroxy benzoates is affected due to steric hindrance (Stern et al., 1996, Rice-Evans et al., 1996). Thus because of a single carboxyl group, monohydroxy benzoic acid is weak compared to dihydroxy and trihydroxy benzoic acids in which the activity also depends on the relative positions of the hydroxyl groups (Rice-Evans et al., 1996). In Fractions Ia of the three fruits, the phenolic acids identified include vanillic, iso-vanillic, ferulic, iso-ferulic and gallic acid. All of these possess monophenolic ring and hence are not effective hydrogen donors. Thus the antioxidant activity of the Fraction Ia (phenolic acid fraction) was low. The second least activity of Fraction II of the fruits is possibly due to the glycosylation of the anthocyanins in the fractions. Hopia and Heinonen (1999) indicated that glycosylation of flavonoids at position 3 decreases their activity compared to their aglycones while Shahidi and Wanasundara (1992) and Kapiotis et al. (1997) demonstated that a saturated heterocyclic ring with 7-glycosylsation and a single hydroxyl group on the B ring suppresses the antioxidant activity. The radical scavenging activity of procyanidins is much higher than flavonoid monomers (Hagerman et al., 1998), therefore tannins are more powerful scavengers than flavonoids and phenolic acids. Large molecules are effective scavengers compared to small molecules. Ellagitannins are less active than gallotannins of corresponding size (Yokozawa et al., 1998). This explains the highest antioxidant activity of Fraction $\mathrm{Ib}$ (polymeric flavanols). The maximum activity of the flavonols is derived from the fact that 3-OH group is attached to the 2,3-double bond and is adjacent to the carbonyl at position 4 in the $\mathrm{C}$ ring (Shahidi \& Wanasundara, 1992) which explains comparatively higher antioxidant capacity of Fraction Ic (flavonols).

\section{Acknowledgements}

This research study was financially supported by the Karachi University Scholarship Fund for PhD and the Dean's Research Grant, Faculty of Science, University of Karachi to the corresponding author.

\section{References}

Afanas'ev, I. B., Dorozhko, A. I., Brodskii, A. V., Kostyuk, A., \& Potapovitch, A. I. (1989). Chelating and free radical scavenging mechanism of inhibitory action of rutin and quercetin in lipid peroxidation. Biochemical Pharmacology, 38, 1763-1769. http://dx.doi.org/10.1016/0006-2952(89)90410-3

Frankel, E. N., \& Meyer, A. S. (2000). The problems of using one dimensional methods to evaluate multifunctional foods and biological antioxidants. Journal of the Science of Food and Agriculture, 80, 1925-1941. http://dx.doi.org/10.1002/1097-0010(200010)80:13<1925::AID-JSFA714>3.0.CO;2-4

Gordon, M. F. (1990). The mechanism of antioxidant action in vitro. In B. J. F. Hudson (Ed.), Food Antioxidants (pp. 1-8). London: Elsevier Applied Science. http://dx.doi.org/10.1007/978-94-009-0753-9_1

Gupta, M. K., Lagarkha, R., Sharma, D. K., Sharma, P. K., Singh, R., \& Ansari, H. S. (2007). Antioxidant activity of the successive extracts of Grewia asiatica leaves. Asian Journal of Chemistry, 19(5), 3417-3420.

Hagerman, A. E., Riedl, K. M., Jones, G. A., Sovik, K. N., Ritchard, N. T., Hartzfield, P. W., \& Riechel, T. L. (1998). High molecular weight plant polyphenolics (tannins) as biological antioxidants. Journal of Agricultural and Food Chemistry, 46(5), 1887-1892. http://dx.doi.org/10.1021/j9970975b

Halliwell, B. (1990). How to characterize a biological antioxidant. Free Radical Research Communication, 9(1), 1-32. http://dx.doi.org/10.3109/10715769009148569

Halliwell, B., Gutteridge, J. M. C., \& Cross, E. E. J. (1992). Free radicals, antioxidants, and human disease: where are we now. Journal of Laboratory and Clinical Medicine, 119, 598-620. http://dx.doi.org/10.1080/10408399509527682

Halliwell, B., Murcia, M. A., Chirico, S., \& Aruoma, O. I. (1995). Free radicals and antioxidants in food and in vivo: what they do and how they work. Critical Reviews in Food Science and Nutrition, 35, 7-20. 
Heinonen, I. M., Meyer, A. S., \& Frankel, E. N. (1998). Antioxidant activity of berry phenolics on human lowdensity lipoprotein and liposome oxidation. Journal of Agricultural and Food Chemistry, 46(10), 4107-4112. http://dx.doi.org/10.1021/jf980181c

Hopia, A., \& Heinonen, M. (1999). Antioxidant activity of flavonol aglycones and their glycosides in methyl linoleate. Jounal of the American Oil Chemists' Society, 76(1), 139-144.

Hossain, S. J., Tsujiyama, I., Takasugi, M., Islam, M. A., Biswas, R. S., \& Aoshima, H. (2008). Total phenolic content antioxidative anti-amylase, anti-glucosidase, and antihistamine release activities of Bangladeshi fruits. Food Science and Technology Research, 14(3), 261-268. http://dx.doi.org/10.3136/fstr.14.261

Jayaprakasha. G. K, Singh. R. P., \& Sakariah, K. K. (2001). Antioxidant activity of grape seed (Vitis vinefera) extracts on peroxidation models in vitro. Food Chemistry, 73, 285-290. http://dx.doi.org/10.1016/S0308-8146(00)00298-3

Jayaprakasha, G. K., Tamil, Selvi. A., \& Sakariah, K. K. (2003). Antimicrobial and antioxidant activities of grape (Vitis vinifera) seed extracts. Food Research International, 36, 117-122. http://dx.doi.org/10.1016/S0963-9969(02)00116-3

Kapiotis, S., Hermann, M., Held, I., Seelos, C., Ehringer, H., \& Gmeiner, B. M. K. (1997). Genistein, the dietary-derived angiogenesis inhibitor, prevents LDL oxidation and protects endothelial cells from damage by atherogenic LDL. Arteriosclerosis, Thrombosis, and Vascular Biology, 17(11), 2868-2874. http://dx.doi.org/10.1161/01.ATV.17.11.2868

Miliauskas, G., Venskutonis, P. R., \& van Beek, T. A. (2004). Screening of radical scavenging activity of some medicinal and aromatic plant extracts. Food Chemistry, 85, 231-237. http://dx.doi.org/10.1016/j.foodchem.2003.05.007

Pin-Der, D. (1998). Antioxidant activity of Budrock (Arctium lappa L.): its scavenging effect on free radical and active oxygen. Journal of the American Oil Chemists Society, 75, 455-461. http://dx.doi.org/10.1007/s11746-998-0248-8

Rice-Evans, C. A., Miller, N., \& Paganga, G. (1996). Structure-antioxidant activity relationships of flavonoids and phenolic acids. Free Radical Biology \& Medicine, 20(7), 933-956. http://dx.doi.org/10.1016/0891-5849(95)02227-9

Rice-Evans, C. A., Miller, N. J., Bolwell, P. G., BramLey, P. M., \& Pridham, J. B. (1995). The relative antioxidant activities of plant-derived polyphenolic flavonoids. Free Radical Research, 22(4), 375-383. http://dx.doi.org/10.3109/10715769509145649

Shahidi, F., \& Wanasundara, P. K. J. P. D. (1992). Phenolic antioxidants. Critical Reviews in Food Science and Nutrition, 32(1), 67-103. http://dx.doi.org/10.1080/10408399209527581

Siddiqi, R., Naz, S., Ahmad, S., \& Sayeed, S. A. (2011) Antimicrobial activity of the polyphenolic fractions derived from Grewia asiatica, Eugenia jambolana and Carissa carandas. International Journal of Food Science and Technology, 46, 250-256. http://dx.doi.org/10.1111/j.1365-2621.2010.02480.x

Skerget, M., Kotnik, P., Hadolin, M., Hras, A. R., Simonic, M., \& Knez, Z. (2005). Phenols, proanthocyanidins, flavones and flavonols in some plant materials and their antioxidant activities. Food Chemistry, 89, 191-198. http://dx.doi.org/10.1016/j.foodchem.2004.02.025

Stern, J. L., Hagerman, A. E., Steinberg, P. D., \& Mason, P. K. (1996). Phlorotannin-protein interactions. Journal of Chemical Ecology, 22(10), 1877-1899. http://dx.doi.org/10.1007/BF02028510

Tanaka, M., Kuie, C. W., Nagashima, Y., \& Taguchi, T. (1988). Application of antioxidative maillard reaction products from histidine and glucose to sardine products. Nippon Suisan Gakkaishi, 54, 1409-1414. http://dx.doi.org/10.2331/suisan.54.1409

Thomas, M. J. (1995). The role of free radicals and antioxidants: how do we know that they are working? Critical Reviews in Food Science and Nutrition, 35, 21-39. http://dx.doi.org/10.1080/10408399509527683

Veigas, J. M., Narayan, M. S., Laxman, P. M., \& Neelwarne, B. (2007). Chemical nature, stability and bioefficacies of anthocyanins from fruit peel of Syzygium cumini Skeels, Food Chemistry, 105(2), 619-627. http://dx.doi.org/10.1016/j.foodchem.2007.04.022

Vinson, J. A., Dabbagh, Y. A., Serry, M. M., \& Jang, J. (1995). Plant flavonoids, especially tea flavonols, are powerful antioxidants using an in vitro oxidation model for heart disease. J. Agric. Food Chem., 43(11), 2800-2802. http://dx.doi.org/10.1021/jf00059a005 
Wang, H., Cao, G., \& Prior, R. L. (1996). Total antioxidant capacity of fruits. Journal of Agricultural and Food Chemistry, 44(3), 701-705. http://dx.doi.org/10.1021/jf950579y

Wrolstad, R. E., Durst, R. W., \& Lee, J. (2005). Tracking colour and pigment changes in anthocyanin products. Trends in Food Science and Technology, 16, 423-428. http://dx.doi.org/10.1016/j.tifs.2005.03.019

Yokozawa, T., Chen, C. P., Dong, E., Tanaka, T., Nonaka, G. I., \& Nishioka, I. (1998). Study on the inhibitory effect of tannins and flavonoids against the 1,1-diphenyl-2-picrylhydrazyl radical. Biochemical Pharmacology, 56(2), 213-222. http://dx.doi.org/10.1016/S0006-2952(98)00128-2

Zhishen, J., Mengcheng, T., \& Jianming, W. (1999). The determination of flavonoid contents in mulberry and their scavenging effects on superoxide radicals. Food Chemistry, 64, 555-559. http://dx.doi.org/10.1016/S0308-8146(98)00102-2 